\title{
An exposure assessment model of the prevalence of Salmonella spp. along the processing stages of Brazilian beef
}

\author{
Ursula Gonzales-Barrón ${ }^{1}$, Luciana Piza ${ }^{2}$, Cristina Xavier', \\ Ernane Costa $^{2}$ and Vasco Cadavez ${ }^{1}$
}

\begin{abstract}
Beef cattle carrying Salmonella spp. represents a risk for contamination of meat and meat products. This study aimed to build an exposure assessment model elucidating the changes in Salmonella prevalence in Brazilian beef along the processing stages. To this effect, the results of a number of published studies reporting Salmonella incidences were assembled in order to model conversion factors based on beta distributions representing the effect of every production stage on the Salmonella incidence on beef carcasses. A random-effects meta-analysis modelled the hide-to-carcass transfer of Salmonella contamination. The Monte Carlo simulation estimated the Salmonella prevalence in beef cuts from processing plants to be $\sim 6.1 \%$ (95\% Cl: $1.4-17.7 \%)$, which was in reasonable agreement with a pool $(n=105)$ of surveys' data of Salmonella in Brazilian beef cuts (mean 4.9\%; 95\% Cl: 1.8-11.5\%) carried out in commercial establishments. The results not only underscored the significant increase in Salmonella prevalence that can occur during evisceration/splitting and boning but also reinforced that, when hygienic slaughter procedures are properly implemented, the load of Salmonella can be reduced at dehiding, rinsing and chilling. As the model was based on a systematic review and meta-analysis, it synthesised all available knowledge on the incidence of Salmonella in Brazilian beef.
\end{abstract}

\section{Keywords}

Simulation, meta-analysis, systematic review, slaughterhouse, beef cuts

Date received: 6 May 2014; revised: 1 September 2014; accepted: 21 October 2014

\section{INTRODUCTION}

Foodborne salmonellosis is a major public health issue in all countries and requires concerted efforts to prevent and control the pathogen in the food supply. In Brazil, a remarkable increase in salmonellosis has been reported. According to the Sanitary Surveillance of the Brazilian Department of Health, from a total of 6791 reported foodborne outbreaks occurring during 1999 to 2010 in Brazil, 46\% of them were caused by Salmonella spp., red meat being the vehicle in $12 \%$ of the outbreaks occurred during the same period (SVS,

Food Science and Technology International 22(1) 10-20

(C) The Author(s) 2014 Reprints and permissions:

sagepub.co.uk/journalsPermissions.nav

DOI: $10.1177 / 1082013214560446$

fst.sagepub.com

ऽAGE
2011). On the other hand, since 2005 , Brazil has become one of the top producers of beef meat in the world with one of the highest annual export rates of over 1.5 millions of tons, which in 2010, represented a share of US\$4.1 billion to the national economy (ABIEC, 2011).

Due to its importance in the international market, the quality and safety of Brazilian beef have to meet

${ }^{1}$ CIMO Mountain Research Centre, School of Agriculture (ESA), Polytechnic Institute of Braganza (IPB), Braganza, Portugal ${ }^{2}$ Faculty of Animal Science, University of São Paulo, São Paulo, Brazil

\section{Corresponding author:}

Ursula Gonzales-Barron, CIMO Mountain Research Centre, School of Agriculture (ESA), Polytechnic Institute of Braganza (IPB), Campus de Santa Apolónia, Apartado 1172, 5301-854 Braganza, Portugal.

Email: ubarron@ipb.pt 
stringent international standards. On the other hand, the sparse information on the occurrence of pathogens in the Brazilian beef meat may have an impact on the international trade, leaving the country in some disadvantage in relation to other large producers such as United States and Australia. In the past few years, meta-analysis has been increasingly applied to synthesize food safety information, such as prevalence of microorganisms in foods, effect of processing steps and interventions, risk ranking of pathogens and disease incidence (Den Besten and Zwietering, 2012; Grieg et al., 2012; Gonzales-Barron et al., 2013; Xavier et al., 2014), and has been used as a tool for exposure assessment models of pathogens in foods (GonzalesBarron and Butler, 2011; Gonzales Barron et al., 2009). Thus, this study aimed to bring together all available information, reported in the literature, on the effects of the different beef processing stages on the occurrence of Salmonella, in order to build an exposure assessment model that could be validated for Brazil. The simulation model was constructed using transfer, reduction and contamination factors modelling the effect of dehiding, evisceration and splitting, rinsing, chilling and boning on the Salmonella occurrence on beef. To model the distribution of the simulation's input variable, the prevalence of Salmonella on Brazilian beef hides postbleeding, a random-effects meta-analysis was conducted to combine the occurrence rates from different Brazilian abattoirs' surveys. In the particular case of the dehiding process, given the many published articles reporting Salmonella occurrence values before and after the operation, a second random-effects meta-analysis was applied to get an overall relative risk with improved precision. Appraisal of the model's ability to produce accurate predictions was performed by comparing the prevalence output estimated by the model against a pool of Salmonella occurrences recovered from Brazilian beef cuts reported in Almeida et al. (2010), Colvara et al. (2007) and Xavier and Joele (2004).

\section{METHODOLOGY}

Hill et al. (2003) devised a slaughterhouse exposure assessment model to estimate, stage by stage, the prevalence of Salmonella on pig carcasses produced in the UK. Such a model employed contamination and reduction factors based on beta distributions modelling uncertainty around prevalence. Those factors were modelled bringing together available results from published literature. In this work, we build upon this type of prevalence modelling by incorporating meta-analytical techniques. However, because there was a data gap on the effect of bleeding on the occurrence of Salmonella on beef hides, the present model assumed that there was no effect of stunning and bleeding on the prevalence of Salmonella on beef hides. The processing stages contemplated by the model were dehiding, evisceration and splitting, rinsing, chilling and boning. Literature identification was conducted using electronic search through Google including combinations of the terms 'Salmonella', 'beef', 'carcass' and a beef processing stage (i.e. 'dehiding') in both English and Portuguese. Suitable scientific articles indexed since 1990 were also identified from bibliographic databases such as PubMed, Science Direct and Scopus using the same keywords. For modelling the contamination and reduction factors, the papers included in this work had to meet two requirements: to present occurrence values before and after a processing stage; and to make use of an approved microbiological method for Salmonella detection clearly stating the extent of the carcass swabbed area. Apart from the latter requirement, for modelling the input variable and for validation, an additional prerequisite was that the study had to be conducted in a Brazilian abattoir.

\section{Transfer factor of Salmonella for the dehiding operation}

Six published studies (Brichta-Harhay et al., 2008; Gandra, 2011; Lanna et al., 2011; Lopes, 2011; Minuzzi et al., 2012; Silva, 2011) were found to report the occurrence values on beef hides after bleeding and on carcasses after dehiding for the same animals. The outcome data from the published studies were available on $n_{T}$ beef hides in the post-dehiding group (treated group) and $n_{C}$ beef carcasses in the pre-dehiding group (control group). The number of successes (Salmonella-positive carcasses or hides) in the postdehiding and pre-dehiding group is represented by $s_{T}$ and $s_{C}$, respectively, and they are compiled in Table 1 . In order to combine all these binary results, a metaanalysis was conducted on the effect size parameterization of the natural logarithm of relative risk $(\log R R)$. $R R$ is defined as the probability of encountering Salmonella-positive beef carcasses after dehiding relative to the probability of encountering Salmonella-positive hides before dehiding. The meta-analysis procedure to obtain an overall (weighted average) $\log R R$ was the one explained in detail in Gonzales-Barron et al. (2013). The same nomenclature was used. Given the significant variability (i.e. heterogeneity) in the outcomes among individual studies, a random-effect solution was opted, which led to an overall $\log R R$ (i.e. effect size of dehiding) of -0.984 and a standard error of 0.262 . Hence, the distribution of the hide-to-carcass transfer factor $\left(T_{D}\right)$ was modelled as

$$
T_{D}=\exp (\operatorname{Normal}(-0.984,0.262))
$$


Table 1. Occurrence of Salmonella-positive bovine carcasses before and after the dehiding operation per sampled batch as detected by six primary studies

\begin{tabular}{|c|c|c|c|c|}
\hline \multirow[b]{2}{*}{ Sources } & \multicolumn{2}{|c|}{$\begin{array}{l}\text { Pre-dehiding } \\
\text { group (control) }\end{array}$} & \multicolumn{2}{|c|}{$\begin{array}{l}\text { Post-dehiding } \\
\text { group (treated) }\end{array}$} \\
\hline & $s_{C}$ & $n_{C}$ & $s_{T}$ & $n_{T}$ \\
\hline \multirow{4}{*}{$\begin{array}{c}\text { Brichta-Harhay } \\
\text { et al. (2008) }\end{array}$} & 106 & 121 & 9 & 18 \\
\hline & 83 & 90 & 21 & 31 \\
\hline & 99 & 106 & 1 & 5 \\
\hline & 108 & 127 & 46 & 84 \\
\hline \multirow[t]{2}{*}{ Gandra (2011) } & 2 & 38 & 0 & 38 \\
\hline & 1 & 22 & 0 & 22 \\
\hline Lanna et al. (2011) & 11 & 135 & 1 & 135 \\
\hline Lopes (2011) & 31 & 200 & 7 & 200 \\
\hline \multirow[t]{2}{*}{ Minuzzi et al. (2012) } & 11 & 200 & 0 & 200 \\
\hline & 6 & 200 & 0 & 200 \\
\hline Silva (2011) & 4 & 120 & 0 & 120 \\
\hline
\end{tabular}

The uncertainty about the Salmonella prevalence on beef carcasses after dehiding $\left(P_{D}\right)$ was calculated as

$$
P_{D}=P_{B} \times T_{D}
$$

where $P_{B}$ is the prevalence of Salmonella on beef hides after bleeding before dehiding.

\section{Contamination factor of Salmonella for the evisceration and splitting operations}

Occurrence values of Salmonella spp. on beef carcasses were recovered from three published studies (Lanna et al., 2011; Minuzzi et al., 2012; Narvaez-Bravo et al., 2013). The following occurrence data were extracted $(s / n): 1 / 135,0 / 200$ and $13 / 237$ before evisceration; and 4/135, 3/200 and 17/237 after splitting from the respective sources. In all cases, a carcass area of $100 \mathrm{~cm}^{2}$ was swabbed. Knowing that the uncertainty about a true prevalence value can be modelled by a beta distribution and that such information can be easily updated through Bayes' theorem (i.e. if the prior opinion about the prevalence is $\operatorname{Bet} a(a, b)$, and the observed number of successes is $s$ out of a sample size of $n$, the posterior distribution turns out to be a $\operatorname{Beta}(a+s, b+n-s))$, the procedure used to model the prevalence about the Salmonella occurrence on preeviscerated carcasses (Vose, 2008) is described as follows: (i) assuming a non-informed prior of $\operatorname{Beta}(1,1)$, the posterior distribution of Salmonella prevalence after the conduction of the study of Lanna et al. (2011) will be a $\operatorname{Beta}(1+1,1+135-1)=\operatorname{Beta}(2,135)$; (ii) now the distribution $\operatorname{Beta}(2,135)$ can be assumed to be a prior and updated using the new occurrence data (Minuzzi et al., 2012), which will produce a posterior $\operatorname{Beta}(2+0$, $135+200-0)=\operatorname{Beta}(2,335)$; and (iii) once again, this $\operatorname{Beta}(2,335)$ can be presumed to be a prior distribution that can be updated using the results from NarvaezBravo et al. (2013), which yields a posterior $\operatorname{Beta}(2+13, \quad 335+237-13)=\operatorname{Beta}(15, \quad 559) . \quad$ The $\operatorname{Beta}(15,559)$ represents the uncertainty about the Salmonella prevalence on beef carcasses before evisceration. Exactly the same procedure was used to model the uncertainty about the Salmonella prevalence after splitting, leading to a $\operatorname{Beta}(25,549)$. Because both beta distributions originated from paired results (i.e. the same primary studies reported incidence values before and after evisceration), the contamination factor of Salmonella for evisceration and splitting $\left(C_{S}\right)$ was built as a ratio of the two prevalence uncertainty distributions

$$
C_{S}=\frac{\operatorname{Beta}(25,549)}{\operatorname{Beta}(15,559)}
$$

The prevalence of Salmonella on Brazilian beef carcasses after evisceration and splitting $\left(P_{S}\right)$ was then estimated as

$$
P_{S}=P_{D} \times C_{S}
$$

\section{Conversion factor of Salmonella for the rinsing operation}

As in the previous sub-section, an after-to-before rinsing conversion factor of the prevalence of Salmonella on beef carcasses was modelled using available results from three published articles. In the Brazilian studies, rinsing had no appreciable effect on the occurrence of Salmonella on beef carcasses: Swabbing a total of 200 beef carcasses, Minuzzi et al. (2012) found that before rinsing three samples were positive while after rinsing four samples were positive. Similarly, Lanna et al. (2011) swabbed a total of 135 carcasses and recovered four positive before rinsing and five positive after rinsing. In the Venezuelan study considered (NarvaezBravo et al., 2013), rinsing the beef carcasses had some beneficial effect for the reduction of Salmonella. Sampling 237 carcasses, Narvaez-Bravo et al. (2013) found that rinsing decreased the number of positive swabs from 17 to 11 . To consider the possibility that the rinsing operation could increase, decrease or have no appreciable effect on the occurrence of Salmonella on beef carcasses, the conversion factor for rinsing $\left(C_{R}\right)$ was modelled integrating the incidence results from the 
three studies in the same way as done for the evisceration and splitting conversion factor. This led to

$$
C_{R}=\frac{\operatorname{Beta}(21,553)}{\operatorname{Beta}(25,549)}
$$

The proportion of Salmonella-positive Brazilian beef carcasses after rinsing $\left(P_{R}\right)$ was estimated as

$$
P_{R}=P_{S} \times C_{R}
$$

\section{Reduction factor of Salmonella for the chilling operation}

In the case of chilling, only one American study (Ruby et al., 2007) was found to report the occurrence of Salmonella on beef carcasses before and after this operation. Making use of a large sample size $(n=5355)$, this study demonstrated that chilling has a decreasing effect on the recovery of Salmonella from beef carcasses. Assuming that such reduction effect obtained in the American abattoirs under evaluation is on average comparable to the one achieved in a common Brazilian beef abattoir, a reduction factor of Salmonella due to chilling $\left(R_{c h}\right)$ was modelled using the results from such study; that is, the positive samples at the entrance to the chiller were 123 out of 5355 and the positive samples after $24 \mathrm{~h}$ chilling were 53 out of 5300 beef carcasses. Using the uninformed $\operatorname{Beta}(1,1)$ as priors for the distributions of prevalence before and after chilling, the $R_{c h}$ was

$$
R_{C h}=\frac{\operatorname{Beta}(53+1,5355-53+1)}{\operatorname{Beta}(123+1,5355-123+1)}
$$

The proportion of Salmonella-positive Brazilian beef carcasses after chilling $\left(P_{C h}\right)$ was estimated as

$$
P_{C h}=P_{R} \times R_{C h}
$$

\section{Contamination factor of Salmonella for the boning operation}

At the point that contaminated carcasses enter the processing plant, the number of contaminated surfaces in the line increases sharply. If contaminated carcasses enter the deboning plant, cross-contamination of conveyor belts, cutting boards and other contact surfaces can occur. The results from the only Brazilian study (Sigarini, 2004) available investigating the effect of deboning on the microbiological quality of beef meat were used to model the contamination in the boning halls. According to Sigarini (2004), by analysing pieces of rump, they observed that the occurrence of Salmonella on beef meat due to boning increased slightly from 0.125 (10 out of 71) to 0.20 (16 out of $80)$. Using the uninformed $\operatorname{Beta}(1,1)$ as a prior for both the prevalence before and after boning, the contamination factor $\left(C_{C}\right)$ due to boning was modelled as

$$
C_{C}=\frac{\operatorname{Beta}(16+1,80-16+1)}{\operatorname{Beta}(10+1,71-10+1)}
$$

The proportion of Salmonella-positive beef cuts $\left(P_{C}\right)$ was then estimated as

$$
P_{C}=P_{C h} \times C_{C}
$$

\section{Model validation using Brazilian data}

The input of the stage-by-stage simulation model was the occurrence of Salmonella on Brazilian beef hides after the bleeding operation $\left(P_{B}\right)$. Data of interest were found from six individual studies and are presented in Table 2. The total number of beef hides swabbed after bleeding is represented by $n_{B}$ while the number of Salmonella-positive samples is given by $s_{B}$. These binary data were combined on the basis that all these studies were conducted in Brazil and that the microbiological methods for determining Salmonella were comparable. Nonetheless, the microbiological protocol from these published studies differed in the hide swabbed area, which was $400 \mathrm{~cm}^{2}$ for some and $100 \mathrm{~cm}^{2}$ for other studies. Since the greater the swabbed area, the higher the likelihood of detecting

Table 2. Data sources utilised for the approximation of the incidence of Salmonella on Brazilian beef hides after the bleeding operation

\begin{tabular}{llll}
\hline & $\begin{array}{l}\text { Number of } \\
\text { Salmonella }(+) \\
\text { samples }\left(s_{B}\right)\end{array}$ & $\begin{array}{l}\text { Total number } \\
\text { of samples } \\
\left(n_{B}\right)\end{array}$ & $\begin{array}{l}\text { Hide } \\
\text { swabbed } \\
\text { area }\left(\mathrm{cm}^{2}\right)\end{array}$ \\
Sources & 5 & 52 & 400 \\
\hline $\begin{array}{c}\text { Souza et al. } \\
(2010)\end{array}$ & 5 & & \\
Lopes (2011) & 31 & 200 & 400 \\
$\begin{array}{c}\text { Lanna et al. } \\
(2011)\end{array}$ & 11 & 135 & 400 \\
Gandra (2011) & 2 & 38 & 100 \\
& 1 & 22 & 100 \\
Silva (2011) & 4 & 120 & 100 \\
Minuzzi et al. & 11 & 200 & 100 \\
$\quad(2012)$ & 6 & 200 & 100 \\
Pooled data & 71 & 967 & \\
\hline
\end{tabular}


contamination, and hence, the higher the occurrence rate; the difference in swabbed area among primary studies had to be accounted for in the integration of the results (Table 2). This integration was done by conducting a separate meta-analysis on the effect size parameterization of the logit transformation of the proportion $p_{j}$ of Salmonella-positive hides after bleeding, which was calculated using the number of successes $s_{B j}$ and the sample size $n_{B j}$ taken from each of the primary studies $j$ (Table 2 ). In the regression, the quantitative variable 'swabbed area' $(A)$ was included as a moderating variable of the meta-analysis model, in order to assess statistically whether area had any effect on the measured occurrence rates of Salmonella on beef hides. The model fitted was of the form

$$
\operatorname{logitp}_{j}=\log \left(\frac{p_{j}}{1-p_{j}}\right)=\beta_{0}+\beta_{1} A_{j}+v_{j}+\varepsilon_{j}
$$

where $\beta_{0}$ is an intercept, $\beta_{1}$ is the fixed effect of the swabbed area, $v_{j}$ the random effects due to the variability among the logit of the true prevalence estimated by each of the primary studies and $\varepsilon_{j}$ the error due to sampling variance. For further details on the procedure to fit a random-effects model with a moderating variable, see Xavier et al. (2014). Since the meta-analysis model confirmed that the swabbed area had a significant effect $(p<0.001)$ on the measured prevalence, the expected Salmonella prevalence on Brazilian beef hides was estimated on the basis of a fail-safe $400 \mathrm{~cm}^{2}$ (mean prevalence 0.125 with a $95 \%$ CI: 0.095-0.164) (Figure 2). With this prevalence estimate, it is possible to calculate the most likely total number of beef hides $s_{B}$ that would have tested positive from a $400-\mathrm{cm}^{2}$ swab, knowing that a total of 967 animals were tested (Table 2). The $s_{B}{ }_{B}$ estimate would then be $0.125 \times 967=121$ total Salmonella-positive beef hides.

The most likely total number of contaminated beef hides $s_{B}$ attempts to quantify the sum of the number of Salmonella-positive hides from the individual studies that would have been likely to be obtained if $400 \mathrm{~cm}^{2}$ of hide samples were swabbed in all individual studies. The most likely $s_{B}$ ' and the total $n_{B}$ from the six studies were then combined using the Bayes' theorem for updating the beta distribution for prevalence, as explained above. Thus, assuming a prior of Beta(1, 1), the uncertainty about the occurrence of Salmonella on Brazilian beef hides after bleeding $\left(P_{B}\right)$ was

$$
P_{B}=\operatorname{Beta}(121+1,967-121+1)
$$

For validation, the output of the model $\left(P_{C}\right)$, fed by Brazilian data, had to be compared to some actual estimate of the occurrence of Salmonella in Brazilian beef cuts. For this, Brazilian survey studies reporting Salmonella occurrences were sought. Three published studies were found (Almeida et al, 2010; Colvara et al., 2007; and Xavier and Joele, 2004) and their results were integrated. Uncertainty was modelled by a beta distribution, as performed for the model's input $P_{B}$. The meta-analysis models were adjusted in $\mathrm{R}$ version 2.14.2 ( $\mathrm{R}$ development Core Team) using the 'metafor' package. The simulation model of the exposure assessment was developed in Microsoft Excel using the@Risk add-in (Industrial Edition version 4.5.2, Palisade, NY), and run for 10,000 iterations using Latin Hypercube sampling without any separation of uncertainty and variability. A sensitivity analysis was carried out in order to identify the key parameters that influence the model's output. The sensitivity of the Salmonella prevalence in beef joints to input values was measured by regression whereby the higher the Pearson correlation coefficient between the input and the output, the more significant the input is in determining the output's value.

\section{RESULTS AND DISCUSSION}

Many studies on the microbiological hygiene (Escherichia coli $\mathrm{O} 157: \mathrm{H} 7$ and Salmonella spp.) of beef cattle at slaughter have shown that animal's faeces and hides are the primary sources of contamination (Arthur et al., 2007; Bell, 1997). The microbial levels of the hides are strongly correlated with carcass contamination, as a result of cross-contamination during processing (Barkocy-Gallagher et al., 2003). Although previous work has shown that there is a substantial transfer of pathogens from hide to carcass during the dehiding operation (McEvoy et al., 2003; Puyalto et al., 1997), no previous attempt was done to quantify such a transfer. In this work, a separate meta-analysis model was used to statistically represent the transfer of contamination from exsanguinated hides to pre-eviscerated beef carcasses. The meta-analysis not only confirmed that, within slaughter batches, there is an association between Salmonella-positive hides and Salmonella-positive carcasses (i.e. a significant transfer of Salmonella from hides to carcass, as indicated by the significant overall $\log R R$ ) but also showed that the Salmonella occurrence on carcasses is lower $(p<0.01)$ than the occurrence on hides. Note that, in the forest plot of Figure 1, all the $\log R R$ estimates from the primary studies are negative. For the simulation model, the random-effects solution was utilised because of the significant heterogeneity $(p<0.01)$ in the measured occurrences from the primary studies.

Because in the Brazilian literature, there is a data gap on the prevalence of Salmonella-positive hides before bleeding, the input of the present model was 


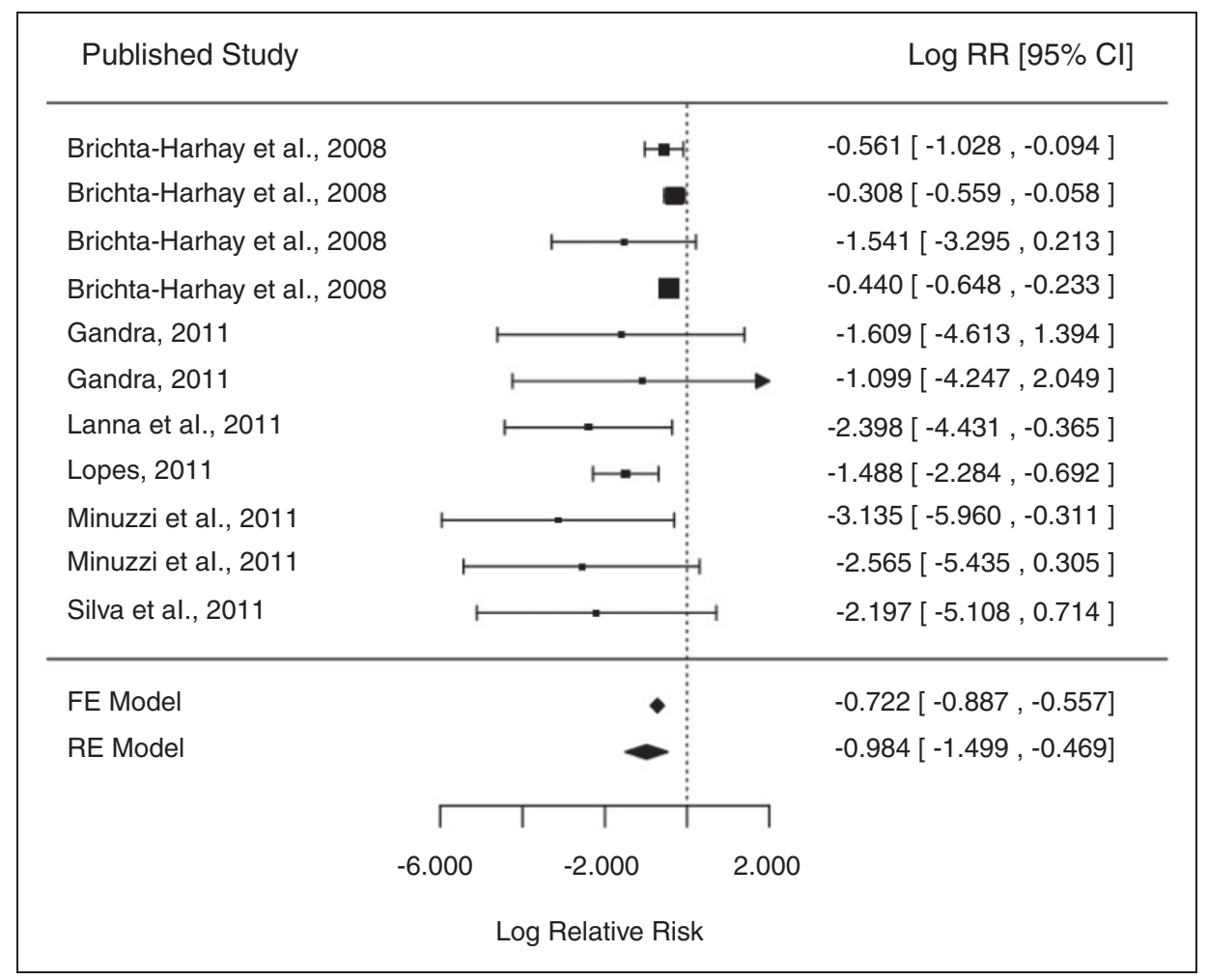

Figure 1. Forest plot of the risk of Salmonella incidence on beef carcasses after dehiding relative to the Salmonella incidence on beef hides after bleeding, among surveyed abattoirs. Size of the square markers reflects the weight assigned to primary studies. Individual estimates and overall relative risk by a fixed-effects (FE) and a random-effects (RE) model are shown with $95 \%$ confidence intervals.

the Salmonella prevalence on exsanguinated hides. The separate meta-analysis conducted on this input's variable corroborated that the extent of swabbed area has a significant influence $(p<0.001)$ on the recovery of Salmonella-positive beef hides. The forest plot of Figure 2 suggests that based on a small swabbed area of $100 \mathrm{~cm}^{2}$, the expected Salmonella-prevalence on Brazilian beef hides would be very low at $4.3 \%$ (95\% CI: $2.9-6.3 \%)$. However, the estimate of Salmonellaprevalence on Brazilian beef hides post-exsanguination used as input of the present simulation model corresponded to the greater area of $400 \mathrm{~cm}^{2}(12.5 \% ; 95 \% \mathrm{CI}$ : 9.5-16.4\%). This estimate appears to be lower than estimates in the range of $18-94 \%$ reported for other countries by Bacon et al. (2002), Brichta-Harhay et al. (2008), Fegan et al. (2005) and Reid et al. (2002). It is also lower than the occurrence of $36.7 \%$ of Salmonella on hides from three large Venezuelan abattoirs, recently surveyed by Narvaez-Bravo et al. (2013). Among other reasons, such as differences in sampling sites, method of Salmonella detection or seasonality, the relatively low value of Salmonella prevalence in Brazilian hides could be partly explained by the extent of the area swabbed in the Brazilian studies which was lower $\left(100-400 \mathrm{~cm}^{2}\right.$ in Table 2) than in the studies mentioned above (hide areas ranging from 750 to $1000 \mathrm{~cm}^{2}$ ). It is worthy to mention that if the difference in swabbed areas had not been accounted for by means of the meta-analysis procedure, and instead, the model's input had been modelled by simply adding together the outcomes of the primary studies (viz. using the total $s_{B}=71$ and total $n_{B}=967$ from Table 2) in a beta $(71+1,967-71+1)$ distribution, the Salmonella prevalence on exsanguinated beef hides produced in Brazil would have been considerably lower at $7.4 \%(95 \%$ CI: $5.9-9.2 \%)$. The use of this value as the simulation model's input would have produced biased estimates of Salmonella-prevalence all along the processing stages.

The model estimated that, after dehiding, the occurrence of Salmonella on Brazilian beef carcasses is significantly lower at an average of $\sim 4.8 \%$ (95\% CI: $2.7-$ $8.0 \%$ in Table 3 ). This model prediction was in good agreement with the results from two Brazilian surveys (Lanna et al., 2011; Lopes, 2011) where Salmonella was recovered with frequencies of $0.7 \%$ and $3.5 \%$ from 135 and 200 carcasses at this point of the chain, respectively. The model estimate was also comparable to the occurrence of Salmonella $(5.5 \%)$ in 237 preeviscerated Venezuelan beef carcasses, surveyed by 


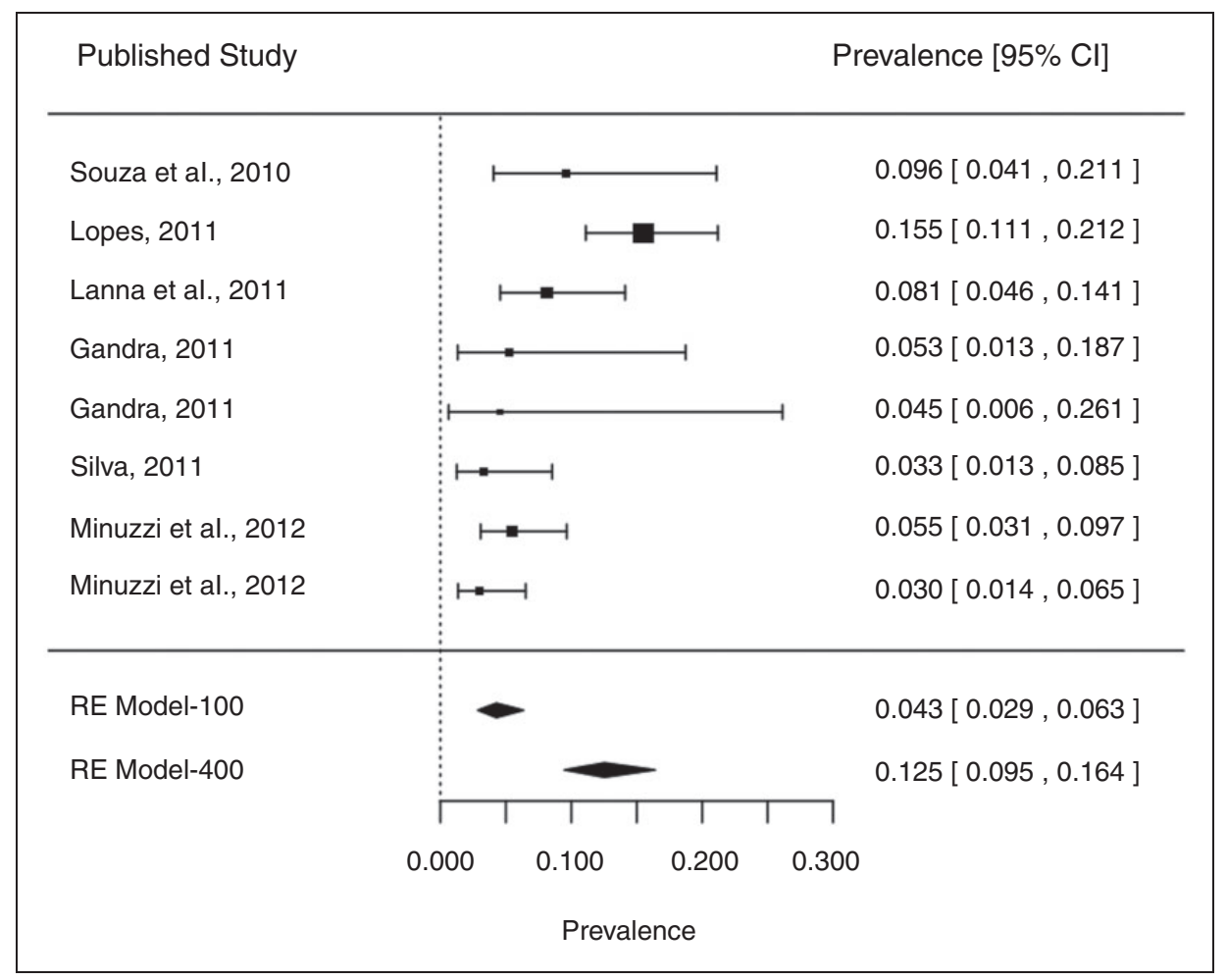

Figure 2. Forest plot of the prevalence of Salmonella spp. in Brazilian beef hides after bleeding. Mean prevalence values based on swabbed areas of 100 and $400 \mathrm{~cm}^{2}$ estimated by a random-effects (RE) meta-analysis models are shown.

Table 3. Means, standard deviations and confidence intervals of the model's outputs for the incidence of Salmonella spp. on Brazilian beef carcasses at the different processing stages

\begin{tabular}{lll}
\hline Prevalence on hide/carcass & Mean (SD) & $95 \% \mathrm{Cl}$ \\
\hline After bleeding (input) & $0.125(0.011)$ & $0.095-0.164$ \\
After dehiding & $0.048(0.014)$ & $0.027-0.080$ \\
After evisceration/splitting & $0.086(0.039)$ & $0.035-0.179$ \\
After rinsing & $0.075(0.042)$ & $0.024-0.182$ \\
After chilling & $0.036(0.021)$ & $0.011-0.091$ \\
After boning & $0.061(0.045)$ & $0.014-0.177$ \\
\hline
\end{tabular}

SD: standard deviation; $\mathrm{Cl}$ : confidence levels.

Narvaez-Bravo et al. (2013). Following carcass evisceration and splitting, the model predicted a significantly higher Salmonella occurrence of 8.6\% (95\% CI: 3.5$17.9 \%$ in Table 3 ), which was expected as there is a positive correlation between the presence of Salmonella in the intestinal faeces from asymptomatic animal carriers and subsequent contamination of carcasses. Through risk factor analysis, Narvaez-Bravo et al. (2013) found that Salmonella carrier animals had eight times higher likelihood of testing positive on hides, three times higher likelihood to test positive on pre-eviscerated carcasses, and two times greater likelihood to test positive on carcasses post-evisceration. The simulation model estimated that the carcass washing step, before carcass entry into the cooler, has little effect on the Salmonella occurrence within slaughter groups. Although, on average, there is apparently a numerical reduction from $8.6 \%$ to $7.5 \%$, a comparison between the confidence intervals for Salmonella on eviscerated carcasses (95\% CI: $3.5-17.9 \%$ ) and washed carcasses (95\% CI: $2.4-18.2 \%$ in Table 3) evidences that, taking groups of carcasses, the washing operation could either increase or decrease the contamination. Buncic and Sofos (2012) explained that carcass washing per se could even further spread the microbial contamination to uncontaminated areas of the carcass if there was not previous removal of the contaminated area by knife trimming. On the other hand, Koohmaraie et al. (2005) explained that further reductions in contamination can be attained by a series of carcass washing steps such as pre-evisceration wash of hot water or organic acid, rinsing with heated water or steam after splitting and a heated organic acid rinse before carcasses enter the final sales cooler. The model's estimate after rinsing was again in reasonable agreement with the Salmonella occurrence rates reported for Brazil by Lanna et al. (2011), Lopes (2011), Minuzzi et al. (2012) and Souza et al. (2010), who recovered, respectively, 
$3.7 \%(5 / 135), 3.0 \%(6 / 200), 2.0 \%(4 / 200)$ and $1.9 \%$ $(1 / 52)$ of Salmonella-positive carcass swabs after final rinsing. Nonetheless, the prevalence of Salmonella in pre-chill beef carcasses produced in Brazil, as estimated by the model $(7.5 \%)$, is higher than the mean occurrence from Spanish (3.8\%) and Italian (3.2\%) slaughterhouses (EFSA, 2012), which were the countries reporting the highest contamination of Salmonella in beef in the European Union. The average occurrence of Salmonella on pre-chill beef carcasses from European slaughterhouses is quite low at $0.2 \%$ (EFSA, 2012).

The model suggested that the process of cooling and chilling has a significant effect on the recovery of Salmonella cells from beef carcasses, reducing the occurrence approximately by half on average $(3.6 \%$; 95\% CI: $1.1-9.1 \%$; Table 3). At this stage, the model's output could not be assessed with the results of Brazilian studies given the absence of Salmonella surveys on post-chill beef carcasses. However, our model's output is comparable to the results of a survey from a Mexican slaughterhouse where Salmonella was recovered in $6 \%$ of the beef carcasses sampled after $24 \mathrm{~h}$ of dry chilling (Narvaez-Bravo et al., 2010). Slightly lower occurrences were surveyed from two American studies involving very large surveys at beef abattoirs: Rose et al. (2002) and Ruby et al. (2007) found that 3\% (125/4042) and 1\% (53/5355) of post-chill beef carcasses tested positive for Salmonella spp. The simulation model estimated that the prevalence of Salmonella in Brazilian beef cuts is on average $6.1 \%$. Figure 3 shows the histogram of the model's output representing the uncertainty around that average value $(6.1 \%)$. Superimposed is the best-fit Gamma distribution, Gamma (2.0990, 0.0271). For validation, this final output was compared to a pool of surveys' data extracted from Almeida et al. (2010), Colvara et al. (2007) and Xavier and Joele (2004) who tested a total of 103 deboned beef cuts from Brazilian commercial beef processing plants using an excision microbiological protocol. Although our model's output implicitly expresses the prevalence based on positive swabs while the validation results express the occurrence in terms of positive excised meat, both outcomes are still comparable. The pool of the validation surveys' data (mean $4.9 \%$; 95\% CI: $1.8-11.5 \%$ ) was well within the $95 \%$ confidence interval $(1.4-17.7 \%$ in Table 3$)$ of the model's final output (Figure 3). The distribution shape found by simulation, considerably wide and skewed, may reflect the substantial variation in the prevalence on Salmonella among production batches and among slaughterhouses. If the model's input variable had not

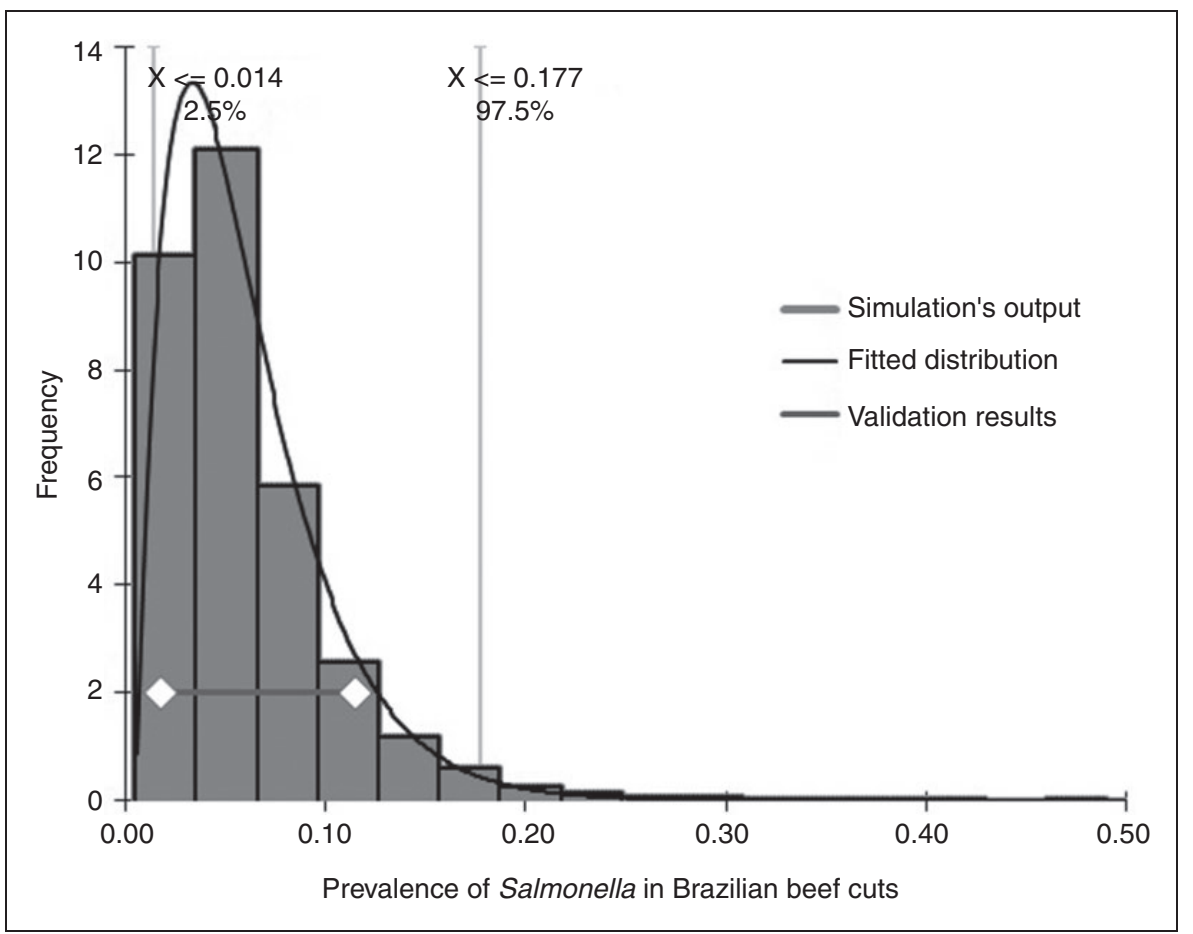

Figure 3. Output distribution of the prevalence of Salmonella spp. in beef cuts produced in Brazil showing $95 \%$ confidence interval as estimated by the stage-by-stage simulation model. The $95 \%$ confidence interval of the validation results is superimposed. 
been corrected for the difference in swabbed areas, the output of the simulation model would have been $3.6 \%$ (95\% CI: $0.8-10.6 \%$ ) of Salmonella-positive Brazilian beef cuts, suggesting that the model would have slightly underestimated the validation surveys' data.

The sensitivity analysis performed on the model's output warned that the increase in Salmonella prevalence that can be attained during boning and evisceration may have a stronger influence on the final prevalence on beef cuts than the reduction in contamination that can occur during dehiding, rinsing and chilling (Figure 4). Depending upon how rinsing is performed, it may not have a strong impact $(r=-0.132)$ on the reduction of Salmonella prevalence on beef carcasses. The high correlation between the model's output with the contamination factor due to boning $(r=0.423)$ and the contamination factor due to evisceration and splitting $(r=0.392)$ reinforces the notion that good manufacture and good hygiene practices should at all times be observed during such critical stages. Reassuringly, the initial prevalence of Salmonella on beef hides (model's input) seemingly does not determine the contamination in the beef cuts at the end of processing (low $r=0.112$ ). This implies that, if contaminated bovine hides entered the abattoir, and yet good practices were observed throughout slaughter, the occurrence of Salmonella in the final product can still be lowered during dehiding, rinsing and chilling. Koohmaraie et al. (2005) sustained that, generally, the prevalence of pathogens on hides is much higher than the carcass contamination rates; and that, although such carcass contamination rate is the highest immediately after hide removal, it consistently declines during processing.

Because of data gaps, this exposure assessment model did not assess quantitatively the effects of intervention strategies to bring down the prevalence of Salmonella in Brazilian-produced beef. Nonetheless, it highlighted that such prevalence is relatively high (in comparison to estimates for America and the EU) and action measures should be taken. Intervention strategies such as hide washing after exsanguination, preevisceration carcass washing, pre-evisceration organic

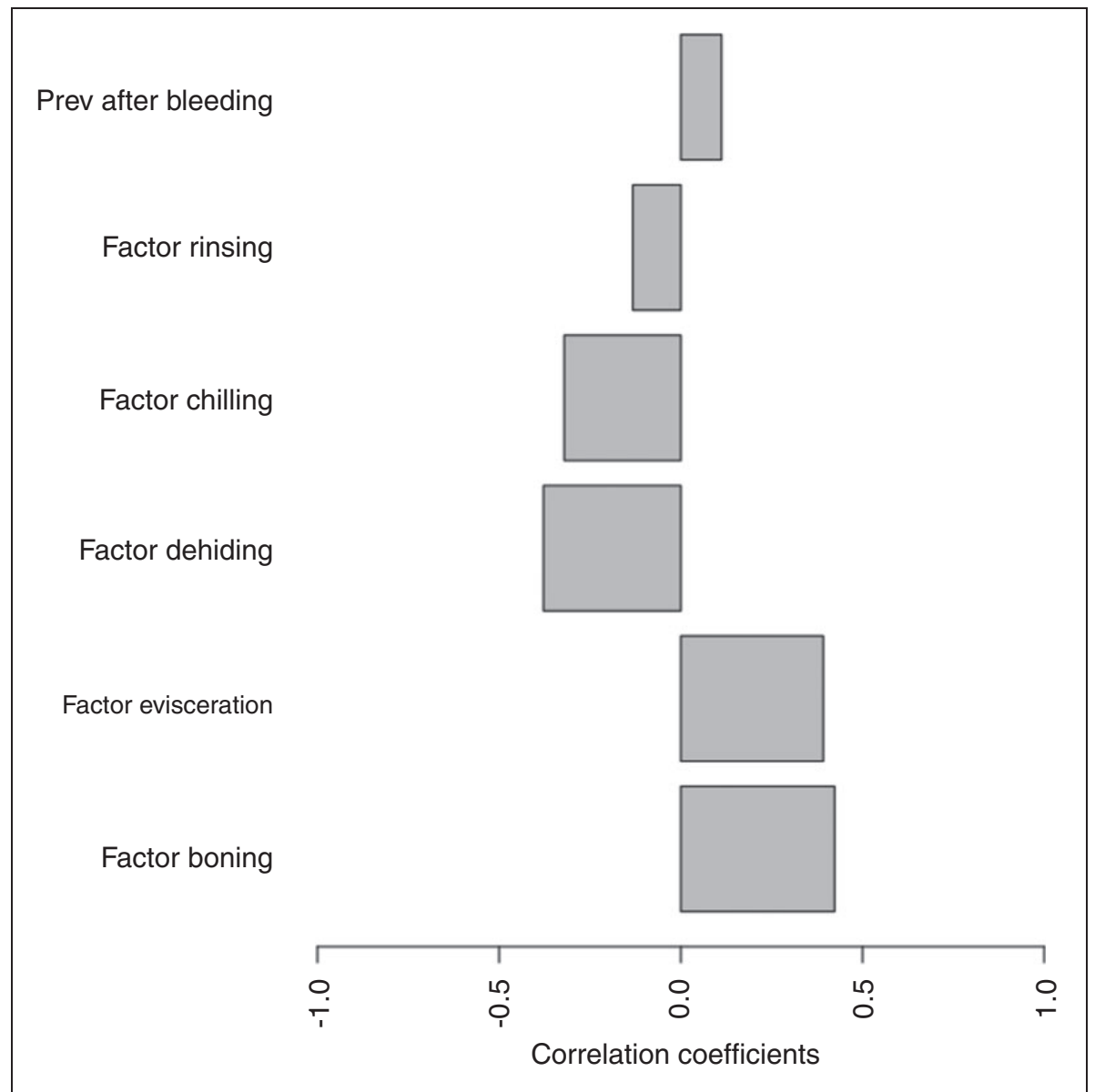

Figure 4. Sensitivity of the prevalence of Salmonella in beef cuts to the total uncertainty of individual variables. 
acid solution rinsing, hot water carcass washing, postevisceration final carcass washing or post-evisceration organic acid solution rinsing should be considered (Koohmaraie et al., 2005). Other data gaps encountered were the occurrence of Salmonella on beef hides before stunning and bleeding, and the limited information to model the effect of jointing on the occurrence of Salmonella on beef as well as the cross-contamination in processing plants. Furthermore, because of data gaps, the model was not developed for any specific Salmonella serovar, although the most common in Brazilian beef has been found to be Infantis, Enteritidis, Newport, Saintpaul and Anatum (Lopes, 2011; Silva, 2011). The exposure assessment model was developed considering only Salmonella occurrence values due to the limited information available on concentrations or most probable number values in Brazilian beef. Nevertheless, the model met the objective of synthesising all available research to date on Salmonella during processing of beef in Brazil. Finally, given the good agreement between the model predictions of Salmonella prevalence and the outcomes from Brazilian surveys along the different processing stages, it can be said that this model, integrating input distributions justified by published studies, approximates fairly well the contamination of Salmonella in Brazilian beef abattoirs.

\section{CONCLUSIONS}

Increasing our understanding of the variation in Salmonella contamination present on the beef hides and carcasses during processing is an important prerequisite for risk analysis and process control assessment. Our exposure assessment model, which integrated all up-to-date knowledge on Salmonella in Brazilian beef along processing, predicts a Salmonella prevalence of $6.1 \%$ (95\% CI: $1.4-17.7 \%)$ in beef produced at Brazilian processing plants, which was in close agreement with the occurrence estimates from surveys at commercial establishments $(4.9 \% ; 95 \%$ CI: $1.8-$ $11.5 \%)$. The model also underscored that the stages of evisceration/splitting and boning are highly critical, as they may largely amplify the contamination of Salmonella spp. Although the hides of animals carrying Salmonella constitute the major source of contamination, the spread of this pathogen during the process can be still minimised by the correct implementation of food safety programs. To this respect, the model demonstrated that the load of Salmonella spp. that initially enters the plant with the live animals does not determine the extent of contamination in the final product. When hygienic slaughter procedures and sanitary programs are working properly, the initial Salmonella load can still be decreased at the stages of dehiding, rinsing and chilling.

\section{FUNDING}

Gonzales-Barron wishes to acknowledge the financial support provided by Portuguese Foundation for Science and Technology (FCT) through the award of a five-year Investigator Fellowship (IF) in the mode of Development Grants (IF/00570).

\section{REFERENCES}

ABIEC. (2011). Bovine meat exports in Brazil. Associação Brasileira das Indústrias Exportadoras de Carne. Available at: www.abiec.com.br/41_exportacao_ano.asp. (accessed 03 February 2014) (In Portuguese).

Almeida AC, Souza RM, Pinho L, Sobrinho EM and Silva BCM. (2010). Determination of microbiological hazards in bovine meat from unregistered slaughterhouses and illegal commerce. Acta Veterinária Brasílica 4(4): 278-285. (In Portuguese).

Arthur TM, Bosilevac JM, Brichta-Harhay DM, Kalchayanand N, Shackelford SD, Wheeler TL, et al. (2007). Effects of a minimal hide wash cabinet on the levels and prevalence of Escherichia coli $\mathrm{O} 157: \mathrm{H} 7$ and Salmonella on the hides of beef cattle at slaughter. Journal of Food Protection 70(5): 1076-1079.

Bacon RT, Sofos JN, Belk KE, Hyatt DR and Smith GC. (2002). Prevalence and antibiotic susceptibility of Salmonella isolated from beef animal hides and carcasses. Journal of Food Protection 65(2): 284-290.

Barkocy-Gallagher GA, Arthur TM, Rivera-Betancourt M, Nou X, Shackelford SD, Wheeler TL, et al. (2003). Seasonal prevalence of Shiga toxin-producing Escherichia coli, including O157:H7 and non-O157 serotypes, and Salmonella in commercial beef processing plants. Journal of Food Protection 66(11): 1978-1986.

Bell RG. (1997). Distribution and sources of microbial contamination on beef carcasses. Journal of Applied Microbiology 82(3): 292-300.

Brichta-Harhay DM, Guerini MN, Arthur TM, Bosilevac JM, Kalchayanand N, Shackelford SD, et al. (2008). Salmonella and Escherichia coli O157:H7 contamination on hides and carcasses of cull cattle presented for slaughter in the United States: an evaluation of prevalence and bacterial loads by immunomagnetic separation and direct plating methods. Applied and Environmental Microbiology 74(20): 6289-6297.

Buncic S and Sofos J. (2012). Interventions to control Salmonella contamination during poultry, cattle and pig slaughter. Food Research International 45(2): 641-655.

Colvara JG, Bueno F, Lima AS and Silva WP. (2007). Occurrence of Salmonella spp. in bovine meat produced in the south of Rio Grande do Sul. XVI Congress of Scientific Initiation, Eliseu Maciel Faculty of Agronomy, Lima, Brazil. Available at: www2.ufpel.edu.br/cic/2007/ cd/pdf/CA/CA_00517.pdf (accessed 26 February 2014) (In Portuguese).

Den Besten HMW and Zwietering MH. (2012). Meta-analysis for quantitative microbiological risk assessments and benchmarking data. Trends in Food Science and Technology 25(1): 34-49. 
EFSA. (2012). The European Union summary report on trends and sources of zoonoses, zoonotic agents and food-borne outbreaks in 2010. EFSA Journal 10(3): 2597.

Fegan N, Vanderlinde P, Higgs G and Desmarchelier P. (2005). A study of the prevalence and enumeration of Salmonella enterica in cattle and on carcasses during processing. Journal of Food Protection 68(6): 1147-1153.

Gandra TV. (2011). Identification of points of contamination by Salmonella and hygiene quality indicators in the slaughter and processing of bovines. Master Thesis, Federal University of Pelotas, Brazil (In Portuguese).

Gonzales-Barron U, Cadavez V, Sheridan J and Butler F. (2013). Modelling the effect of chilling on the occurrence of Salmonella on pig carcasses at study, abattoir and batch levels by meta-analysis. International Journal of Food Microbiology 163(2-3): 101-113.

Gonzales-Barron U and Butler F. (2011). The use of metaanalytical tools in risk assessment for food safety. Food Microbiology 28(4): 823-827.

Gonzales Barron U, Soumpasis I, Butler F, Duggan S, Prendergast D and Duffy G. (2009). Estimation of prevalence of Salmonella spp. on pig carcasses and pork joints using a quantitative risk assessment model aided by metaanalysis. Journal of Food Protection 72(2): 274-285.

Grieg JD, Waddell L, Wilhelm B, Wilkins W, Bucher O, Parker S, et al. (2012). The efficacy of interventions applied during primary processing on contamination of beef carcasses with Escherichia coli. Food Control 27(2): 385-397.

Hill A, England T, Snary E, Cook A, Kelly L, Evans S, et al. (2003). A farm-to-consumption risk assessment for Salmonella Typhimurium in pigs. Report, Veterinary Laboratories Agency, Weybridge, UK.

Koohmaraie M, Arthur TM, Bosilevac JM, Guerini M, Shackelford SD and Wheeler TL. (2005). Post-harvest interventions to reduce/eliminate pathogens in beef. Meat Science 71(1): 79-91.

Lanna FG, Cossi MV, Dias MR, Almeida MV, Camargo AC, Pinto PS, et al. (2011). Occurrence of Salmonella at different stages in the slaughter line of bovines. In: Proceedings of the 26th Brazilian Congress of Microbiology, Foz do Iguaçu, Brazil (In Portuguese).

Lopes JT. (2011). Salmonella spp. in the production chain of export bovine meat: Occurrence, antimicrobial susceptibility profile, virulence genes and macro-restriction profile by PFGE. Master Thesis, University of São Paulo, Brazil (In Portuguese).

McEvoy JM, Doherty AM, Sheridan JJ, Thomson-Carter FM, Garvey P, McGuire L, et al. (2003). The prevalence and spread of Escherichia coli $\mathrm{O} 157: \mathrm{H} 7$ at a commercial beef abattoir. Journal of Applied Microbiology 95(2): 256-266.

Minuzzi MD, Gandra TK, Iglesias MA, Decol LT and Silva WP. (2012). Salmonella spp. in two bovine abattoirs - region of Rio Grande do Sul. In: Proceedings of the 21st Congress on Scientific Initiation, Pelotas, Brazil. Available at: www2.ufpel.edu.br/cic/2012/anais/pdf/CA/
CA_01251.pdf (accessed 12 February 2014) (In Portuguese).

Narvaez-Bravo C, Rodas-González A, Fuenmayor Y, Flores-Rondón C, Carruyo G, Moreno M, et al. (2013). Salmonella on faeces, hides and carcasses in beef slaughter facilities in Venezuela. International Journal of Food Microbiology 166(2): 226-230.

Narvaez-Bravo C, Miller MF, Echeverry A, Pond K and Brashears MM. (2010). Salmonella and E. coli O157:H7 prevalence in cattle and on carcasses in a vertically integrated feedlot and harvest plant in Mexico. In: Proceedings of the 97th Annual Meeting of the International. Association for Food Protection, Anaheim, California, pp.786-795.

Puyalto C, Colmin C and Laval A. (1997). Salmonella Typhimurium contamination from farm to meat in adult cattle. Descriptive study. Veterinary Research 28(5): 449-460.

Reid CA, Small A, Avery SM and Buncic S. (2002). Presence of food-borne pathogens on cattle hides. Food Control 13(6-7): 411-415.

Rose BE, Hill WE, Umholtz R, Ransom GM and James WO. (2002). Testing for Salmonella in raw meat and poultry products collected at federally inspected establishments in the United States, 1998 through 2000. Journal of Food Protection 65(6): 937-947.

Ruby JR, Zhu J and Ingham SC. (2007). Using indicator bactéria and Salmonella test results from three largescale beef abattoirs over an 18 -month period to evaluate intervention system efficacy and plan carcass testing for Salmonella. Journal of Food Protection 70(12): 2732-2740.

Sigarini CO. (2004). Avaliação bacteriológica da carne bovina desossada em estabelecimentos comerciais do Municipio de Cuiabá-MT Brasil. Master Thesis, Federal University of Fluminense, Niterói, Brazil.

Silva FF. (2011). Investigação de Salmonella spp. e microrganismos indicadores em carcacas bovinas durante o processamento em abatedouro-frigorifico. Master Thesis, Federal University of Rio Grande do Sul, Brazil.

Souza MV, Aragão SC, Matos AVR, Xavier DM, Pinto JPAN and Biondi GF. (2010). Pesquisa de Salmonella spp. na linha de abate de bovinos. Available at: www. sovergs.com.br/site/higienistas/trabalhos/10211.pdf (accessed 12 February 2014).

SVS. (2011). Doenças transmitidas por alimentos: Aspectos epidemiológicos 1999-2010. Available at: http://portal. saude.gov.br/portal/saude/profissional/visualizar texto.cfm?idtxt $=31760$ (accessed 04 February 2014).

Vose D. (2008). Risk Analysis. A Quantitative Guide. Chichester, England: John Wiley \& Sons.

Xavier VG and Joele SP. (2004). Avaliação das condições higiênico-sanitárias da carne bovina in natura comercializada na cidade de Belém, PA. Higiene Alimentar 18(125): 64-73.

Xavier C, Gonzales-Barron U, Paula V, Estevinho L and Cadavez V. (2014). Meta-analysis of the incidence of food-borne pathogens in Portuguese meats and their products. Food Research International 55: 311-323. 